\title{
Fundamentals of standard left and right pneumonectomy
}

\author{
Alex Fourdrain, Lucile Gust, Joséphine Chenesseau, Xavier-Benoit D’Journo \\ Thoracic Surgery Department, Aix-Marseille University, CNRS, INSERM, Marseille Cancer Research Center, Assistance-Publique Hôpitaux de \\ Marseille, Marseille, France \\ Correspondence to: Xavier-Benoit D’Journo. Service de Chirurgie Thoracique, Chemin des Bourrely, Hôpital Nord, Aix-Marseille Université, 13915 \\ Marseille cedex 20, France. Email: xavier.djourno@ap-hm.fr.
}

\begin{abstract}
Until a few decades ago, pneumonectomy was the standard of care for resection of non-small cell lung cancer. Because of pneumonectomy higher morbidity and mortality rates, surgeons are nowadays determined to perform lobectomies whenever possible. However, pneumonectomy remains the only surgical option in patients for whom a lobar resection is not technically or oncologically possible, even considering bronchoplastic and/or angioplastic procedures. Close attention is needed in preoperative course and during intraoperative assessment to maintain the indication of pneumonectomy, considering the possibility of a lobar resection, and ruling out a metastatic or non-resectable patient. This paper describes the casual approach for standard left or right pneumonectomy including technical consideration, to achieve safe and complete resection leading to adequate oncological outcomes in lung cancer surgery.
\end{abstract}

Keywords: Pneumonectomy; lung cancer surgery; pulmonary surgical procedure; surgical technique

Received: 04 February 2020; Accepted: 02 March 2020; Published: 10 October 2020.

doi: $10.21037 /$ shc.2020.03.04

View this article at: http://dx.doi.org/10.21037/shc.2020.03.04

\section{Introduction}

The first successful pneumonectomies were performed almost a century ago, in the 1930 's. For a long time, this surgery was considered standard of care for resection of non-small cell lung cancer until a few decades ago. Indeed, surgeons are currently determined to perform lobectomies with or without bronchoplastic or angioplastic reconstruction in order to avoid pneumonectomy (1). Nevertheless, pneumonectomy remains mandatory in some patients to allow complete resection and adequate oncological outcomes (2).

\section{Preoperative and intraoperative considerations}

Pneumonectomy is mostly performed in lung cancer. Subsequently, preoperative workout must be particularly extensive. Patient with metastatic disease, clinical N2 or N3 nodal status, non-resectable tumors (mediastinal extension) must be ruled out. PET-scan and CT-scan examination should be recent (up to one month prior). Suspicion of mediastinal extension should be assessed with thoracic magnetic resonance imaging (MRI) for resectability. Suspicion of pathological N2 or N3 lymph node status should be explored invasively through endobronchial ultrasound (EBUS), mediastinoscopy or thoracoscopy (3). Histological proof of lung cancer should be obtained preoperatively, or at least confirmed intraoperatively through frozen section examination prior to any vascular ligation or bronchial section.

The usual surgical approach for standard pneumonectomy is a thoracotomy through the $5^{\text {th }}$ intercostal space which is most commonly performed through a posterolateral approach, rather than a lateral "axillary" approach. Attention should be given to preserve chest musculature at this point. Indeed, harvesting a muscular flap (latissimus dorsi, serratus anterior) may later be necessary, either during the procedure for bronchial covering or later in case of reoperation for bronchial and/or pleural complication. An intercostal muscle flap can also be harvested during the thoracotomy.

Chest exploration and resectability assessment are then performed prior to pneumonectomy. All adhesions should be divided. The whole pleural cavity must be 


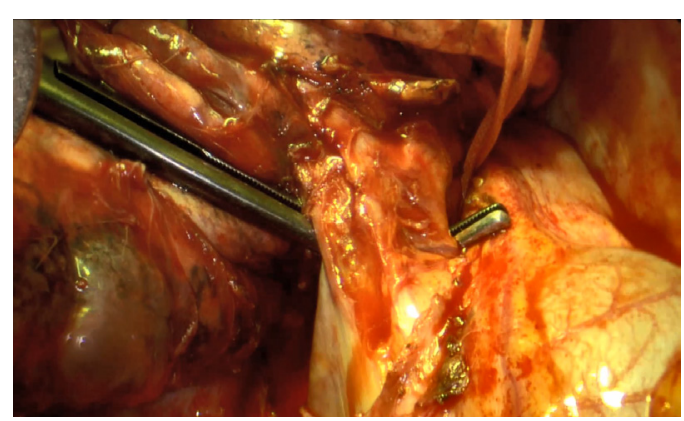

Figure 1 Dissection of the two right pulmonary veins within the pericardium.

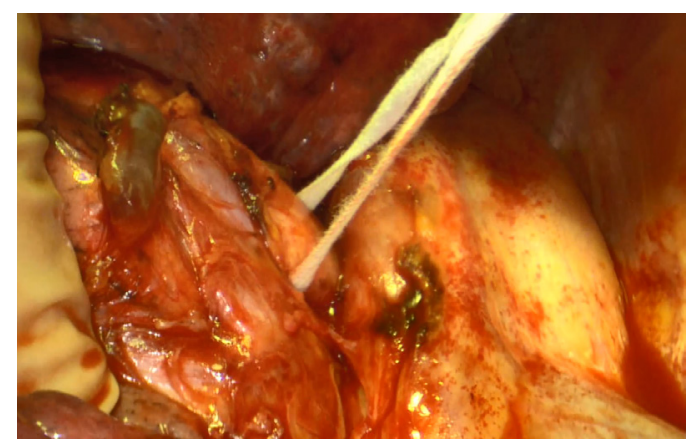

Figure 2 Dissection of the right pulmonary artery.

explored to rule out pleural metastasis or non resectable tumor. Possibility of a parenchymal sparing resection (bronchoplastic and/or angioplastic lobectomy) should also be assessed.

\section{Right pneumonectomy}

Once resectability is confirmed, the first step of a right pneumonectomy is to expose the lower pulmonary vein. The pulmonary ligament is divided, using monopolar or bipolar cautery for small bronchial vessels. Mediastinal pleura is then divided around the hilum to expose the vascular and bronchial elements. The lower pulmonary vein is usually the first vessel to be dissected, then either ligated or stapled. Vascular dissection is then performed from an anterior approach to expose the upper pulmonary vein and isolate the phrenic nerve anteriorly. The upper pulmonary vein is divided from the pulmonary artery using both blunt and sharp dissection, then either ligated or stapled. The two pulmonary veins can be dissected and ligated or stapled at the same time within the pericardium (Figure 1). Exposition of the right pulmonary artery is easier after division of the upper pulmonary vein (Figure 2). Its dissection should be carefully performed, especially around the arising of the mediastinal artery which can occasionally be mistaken for the common trunk of the pulmonary artery. The pulmonary artery is either ligated or stapled.

The last step is to divide the right main bronchus, usually from a posterior approach using sharp dissection then blunt dissection to distally peel the peri-bronchial lymph nodes. The right main bronchus is then divided and ligated or stapled. It is important to obtain the shortest bronchial stump without clamping the tracheobronchial tube, to prevent fistula. After the specimen is extracted, the bronchial stump should be tested for air leaks. Bronchial reinforcement is recommended using intrathoracic tissues such as pleural or pericardial fat, intercostal muscle flap, or parietal muscular flap, based on the operator's preferences and patient's condition. In case of lung cancer surgery, systematic hilar and mediastinal lymph node dissection is mandatory. Some surgeons perform lymphadenectomy prior to pneumonectomy to enhance the bronchial and vascular dissection. After chest closure, a single drain with no suction is used for pleural drainage.

\section{Left pneumonectomy (Video 1)}

Likewise to right pneumonectomy, the first step of a left pneumonectomy is to expose the lower pulmonary vein by dividing the pulmonary ligament. Due to the heart, the space around the left lower pulmonary vein is more narrowed than on the right side. At this point, it is helpful to divide the whole mediastinal pleura around the hilum to expose the vascular and bronchial elements. Usually, the lower pulmonary vein is the first vessel to be divided, and either ligated or stapled. Vascular dissection is then performed from an anterior approach, to expose the upper pulmonary vein and isolate the phrenic nerve anteriorly. The upper pulmonary vein is divided from the left pulmonary artery using both blunt and sharp dissection, then either ligated or stapled. Exposition of the left pulmonary artery is easier after division of the upper pulmonary vein. Division should be carefully performed, especially posteriorly and distally where the pulmonary artery's path becomes posterior to the left main bronchus. The left pulmonary artery is then either ligated or stapled. The main bronchus is then divided, using the same 

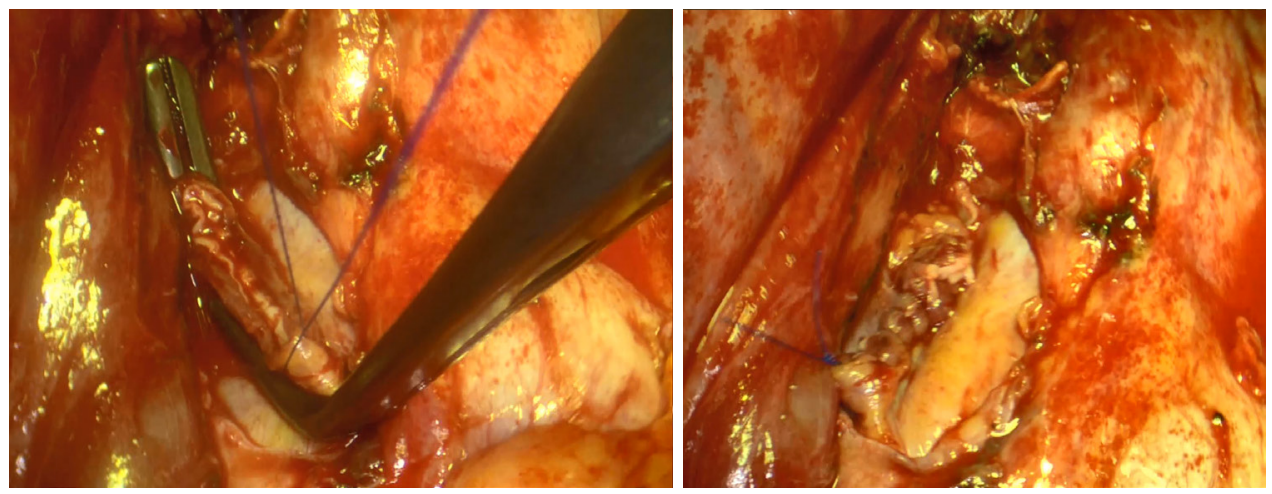

Figure 3 Intrapericardial ligation of right pulmonary veins.

precautions as on the right side.

\section{Technical consideration}

When performing a surgical resection for lung cancer, it has been demonstrated that ligation of pulmonary veins prior to pulmonary artery is associated with a lower rate of locoregional recurrences (4). Surgeons usually divide pulmonary veins in the first place but it may be challenging if they are locally involved. In this case, the pulmonary artery can be clamped or ligated first, intrapericardial venous ligation being the final step of the resection (Figure 3).

Regarding suture technique, the use of a bronchial or vascular mechanical stapler allows a shorter suture time, and is equivalent to manual suture. Indeed, meta-analysis showed no differences regarding these 2 techniques in terms of postoperative bronchopleural fistula (5). Therefore, mechanical stapling should be preferred over manual suture in the case of a standard pneumonectomy. Nevertheless, in some cases where anatomy is more challenging due to local condition, a mechanical stapler may be inadequate and the use of a vascular or bronchial clamp with manual suture is required. For the bronchial stump, we suture the posterior mucosa to the cartilaginous ring with separated non absorbable or slowly absorbable 4/0 stiches. Another possibility is to fold the posterior mucosa inside the cartilaginous ring according to the Overholt technique. Regarding vascular stumps after proximal clamping, we use a $5 / 0$ non absorbable continuous suture.

\section{Conclusions}

Despite higher morbidity and mortality rates, pneumonectomy remains the only surgical option when a lobar resection is not technically or oncologically possible, even considering bronchoplastic and/or angioplastic procedures. A close attention in preoperative course and intraoperative assessment, associated to a carefully performed procedure including a meticulous bronchial stump management should allow a complete resection and lead to adequate oncological outcomes.

\section{Acknowledgments}

Funding: None.

\section{Footnote}

Provenance and Peer Review: This article was commissioned by the Guest Editors (Lorenzo Spaggiari and Luca Bertolaccini) for the series "The Role of Pneumonectomy in Thoracic Surgery in The Third Millennium" published in Shanghai Chest. The article has undergone external peer review.

Conflicts of Interest: All authors have completed the ICMJE uniform disclosure form (available at http://dx.doi. org/10.21037/shc.2020.03.04). The series "The Role of Pneumonectomy in Thoracic Surgery in The Third Millennium" was commissioned by the editorial office without any funding or sponsorship. The authors have no other conflicts of interest to declare.

Ethical Statement: The authors are accountable for all aspects of the work in ensuring that questions related to the accuracy or integrity of any part of the work are appropriately investigated and resolved. All procedures performed in studies involving human participants were in 
accordance with the ethical standards of the institutional and/or national research committee(s) and with the Helsinki Declaration (as revised in 2013). Written informed consent was obtained from the patient for publication of this manuscript and any accompanying images.

Open Access Statement: This is an Open Access article distributed in accordance with the Creative Commons Attribution-NonCommercial-NoDerivs 4.0 International License (CC BY-NC-ND 4.0), which permits the noncommercial replication and distribution of the article with the strict proviso that no changes or edits are made and the original work is properly cited (including links to both the formal publication through the relevant DOI and the license). See: https://creativecommons.org/licenses/by-nc-nd/4.0/.

\section{References}

1. Bagan P, Berna P, Pereira JC, et al. Sleeve lobectomy versus pneumonectomy: tumor characteristics and

doi: 10.21037/shc.2020.03.04

Cite this article as: Fourdrain A, Gust L, Chenesseau J, D'Journo XB. Fundamentals of standard left and right pneumonectomy. Shanghai Chest 2020;4:41. comparative analysis of feasibility and results. Ann Thorac Surg 2005;80:2046-50.

2. Thomas PA, Berbis J, Baste JM, et al. Pneumonectomy for lung cancer: contemporary national early morbidity and mortality outcomes. J Thorac Cardiovasc Surg 2015;149:73-82.

3. De Leyn P, Dooms C, Kuzdzal J, et al. Revised ESTS guidelines for preoperative mediastinal lymph node staging for non-small-cell lung cancer. Eur J Cardiothorac Surg 2014;45:787-98.

4. Sumitomo R, Fukui T, Marumo S, et al. Effects of vessel interruption sequence during thoracoscopic lobectomy for non-small cell lung cancer. Gen Thorac Cardiovasc Surg 2018;66:464-70.

5. Zakkar M, Kanagasabay R, Hunt I. No evidence that manual closure of the bronchial stump has a lower failure rate than mechanical stapler closure following anatomical lung resection. Interact Cardiovasc Thorac Surg 2014;18:488-93. 